always in a plane at right angles to the visual axis. He found that an object is recognized more readily when inverted than when in either of the two intermediate positions, and more readily also than in the erect mirror reversal or in that position inverted.

Dr. Arthur MacDonald reported further measurements of pain and gave tables and results. Two purely philosophical papers were presented, one by Professor W. A. Hammond on the theory of the will in Aristotle's Ethics, and the other by Professor W. G. Everett on 'Ethical Scepticism.' These papers closed the morning session. In the afternoon Professor W. Caldwell read an appreciative criticism of Professor J. Mark Baldwin's recent work on Social and Ethical Interpretation. A paper on the genetic determination of the self, which had been announced by Professor Baldwin, he was forced to abandon on account of illness.

In a 'Study of Geometrical Illusions,' Professor Charles H. Judd upheld the thesis that the underestimation of acute angles and overestimation of obtuse angles, which is a common feature of many illusions, is not a fundamental fact, but is to be explained as due to the false estimation of the length of the sides of the angles.

Professor Margaret F. Washburn spoke on 'Subjective Colors and the After Image,' and Professor Ladd closed the meeting with a description of a new color illusion.

\section{Livingston FarRand.}

\section{SCIENTIFIC BOOKS.}

The New Maryland Geological Survey. Volume I., 1897. Volume II., 1898. Johns Hopkins Press.

The plan and the organization of the Maryland Geological Survey are set forth in the introduction to the first volume of the reports. In many respects they present admirable examples of common sense in scientific work. The business of a State Survey, if successful, must be conducted so that it nets the people a fair return for their money. It may neither soar to abstruse and doubtfully profitable speculation nor sink to politics for spoils only. Failing to avoid one or the other unbusiness-like extreme, many State Surveys have died. The Maryland Survey appears to have struck a course between Scylla and Charybdis.

According to the organic law the name is the State Geological and Economic Survey. The control is in the hands of a commission, con. sisting of the Governor and Comptroller of the State and the presidents of two principal educational institutions - of Johns Hopkins University and the Maryland Agricultural College. The commissioners shall appoint as superintendent a geologist of established reputation, who shall nominate for appointment by them such assistants as they deem necessary; and they shall determine compensation of employees and may remove them. The objects of the Survey are defined in six articles, of which three relate to appropriate investigations having practical bearing, two give authority to publish maps and reports, and the sixth confers special authority to consider 'such other scientific and economic questions as in the judgment of the commissioners shall be deemed of value to the people of the State.' Among other sections is one appropriating $\$ 10,000$ per annum for the purpose of executing the provisions of the act. This section must be repealed before the appropriations for the support of the Survey can cease.

By this law a board of commissioners, which is equally divided between the educational and executive or political leaders of the State, is given unrestricted authority to carry on appropriate observations for the benefit of the people. The scope is unlimited, their power is absolute, their responsibility is direct.

The Commission organized the Survey to insure practical and thorough work. Professor Wm. B. Clark, of Johns Hopkins, was appointed State Geologist. It was resolved that there should be no salaried officers, all services to be paid at per diem rates for the time employed.

The scope of the Survey was determined to be economic and educational. The economic character was sufficiently prescribed by the law ; 
but an educational purpose has rarely, if ever, been so frankly assumed by a State Survey. The necessity to enlighten the general public as to the ends of a geological survey, though well understood, is generally stated in an aside.

The position taken by the Maryland Survey gives it strength and a broader opportunity. It will be thought by many who know him that President Gilman has exercised a controlling influence in this as in other wise decisions of the Board.

Strong in its close relations with the Maryland Agricultural College and Johns Hopkins University, the Maryland Survey has sought still further to strengthen itself by cooperation with the scientific bureaus of the National Government. The Agricultural Department, the Weather Bureau and the Geological Survey have met the State Survey's advances cordially, and the work of Professor Clark and his colleagues is supplemented by that of members of the several National organizations.

Maryland undertakes no new task in organizing this economic survey. Exploration and mapping have been in progress since the earliest days of settlement and thus cover more than two centuries and a half. Logically planned, the reports open with an historical account of this progress, which begins with the voyage of Captain John Smith in 1608. Reading the early accounts of the region about the Chesapeake one is reminded of recent descriptions of Alaska or the Phillipines. The degree of knowledge expressed is similar. In 1635 it was written of Maryland :

"The Countrey is generally plaine and even, and yet hath some pritty small hills and risings ; It's full of Rivers and Creekes and hath store of Springs and smaller Brookes."

"The Mineralls have not yet beene much searched after, yet there is discovered Iron Oare; and Earth fitt to make Allum, Terra lemnia, and a red soile like Bolearmonicke, with sundry other sorts of Mineralls, which wee have not yet beene able to make any tryall of *** and to conclude, there is nothing that can be reasonably expected in a place lying in the latitude which this doth, but you shall either find it here to grow naturally ; or Industry, and good husbandry will produce it."
Modern events were perhaps prophesied in the note on Herman's map of Maryland (1670):

"Certain it is that as the Spaniard is possessed of great Store of Mineralls at the other side of these mountaines the same Treasures they may in process of time afford also to us here on this side when occupyed which is Recomended to Posterity to Remember.'"

The first geological survey of Maryland was authorized by law in 1834. It is interesting to compare that act of the Assembly with the act passed with the same object sixty-two years later. The Act of 1834 authorizes the Governor and Council to appoint an Engineer and a Geologist at salaries of $\$ 2,000$ each ; it prescribes the duties of the engineer and even more precisely those of the geologist. The latter shall " make a complete and minute geological survey of the whole State, commencing with that portion which belongs to the Tertiary order of geological formations, and with the southern division thereof, and progressing regularly with the course of the waters of the Potomac and Chesapeake through that region, and thence through the other subdivisions of the State, with as much expedition and despatch as may be consistent with minuteness and accuracy."

By a special section of the act the Geologist is instructed to analyze mineral substances or soils left at his office or residence by any citizen of the State; he is to report all 'remarkable discoveries," a command whose phraseology sufficiently indicates the common understanding of a survey's raison d'être. The expenses of the Engineer and Geologist are to be paid, "so far as they may be deemed just, equitable and proper, to an amount not exceeding one thousand dollars per annum. But the official services of these gentlemen shall cease at the end of one year, unless the act be re-enacted by the next Legislature.

In strong contrast with the petty control thus assumed by the Assembly of 1834 is the freedom of action granted in 1896, and not less striking is the personal tone of the former act when compared with the impersonal character of the latter one. The one might have been entitled : An act to hamper a State Geologist; the other has created a State Survey.

The historical account is brought down to 
the date of writing by sketches of the work of all existing institutions which are contributing to a knowledge of Maryland's resources. The valuable work of the late Professor G. H. Williams.is appropriately set forth at length. The sketch closes with lists of the surveys and maps relating to Maryland made by the $U$. S. Coast and Geodetic Survey and the U. S. Geological Survey, and these lists are supplemented by excellent index maps of the State, showing the triangulation and the arrangement of map sheets.

Following this historical article by Professor Clark is a second, on the present knowledge of the physical features of Maryland, embracing an account of the physiography, geology and mineral resources. Of this it need only be said that it is concise, complete and accurate, so far as the data now available permit. This report frankly recognizes the existing information concerning the State as the seed from which future knowledge must grow. An excellent geologic map lithographed by Hoen \& Co. illustrates the article.

A bibliography and account of cartography of Maryland, by Dr. E. B. Matthews, logically completes the historical portion of the volume and constitutes an important work of reference.

An earnest of the important results which the Maryland Survey is to accomplish is contained in the article by L. A. Bauer on a magnetic survey of the State. Including an account of the history and objects of magnetic surveys, this preliminary report is of broad general interest. Declination and dip of the needle and intensity of the magnetic forces are defined. A history of magnetic surveys and an account of methods follow. There is an extended account of variations of magnetic declination. The distribution of the declination in Maryland is described and illustrated by a map. And, finally, the economic value of the work is set forth in a discussion of the establishment of surveyor's meridian lines.

The second volume of the Maryland Survey reports, when compared with the first, is a demonstration of the wisdom of doing one thing well and the next thing better. Both volumes are superior in utility and appearance to any
State report previously issued. That the Maryland Survey has already won the confidence of the people and the Legislature is shown by the appropriations of $\$ 5,000$ to promote topographic surveys and $\$ 10,000$ to conduct investigations for betterment in highways. These sums, added to the appropriation of $\$ 10,000$ for geology, place in the hands of the Geological Survey Commission annually $\$ 25,000$ to be spent for the benefit of the people of the State. That it will be expended in securing authoritative information appears from the contents of the second report.

Dr. G. P. Merrill, an authority on building stones, contributes an article on the physical, chemical and economic properties of building stones in general, with special reference to the needs of the Maryland industry. This article is of general interest, as furnishing information of primary importance to capitalists, quarrymen and users of stone. It is followed by an exhaustive description by Dr. Mathews of the quarry products of Maryland considered with reference to their qualities, accessibility and adaptation. The subject is treated in detail, being classified under the headings : 'Granites and Gneisses,' 'Marbles and Limestones,' 'Sandstones,' 'Slate,' and the 'Building Stone Trade,' and further subclassified by localities throughout the State. The author personally examined each quarry and made his observations with expert knowledge. The report is very beautifully illustrated, not only by the usual photographs of quarries, but also by photomicrographs of the rocks and by full-page colored heliotypes which represent the texture and color of the stone as they appear in a smoothed specimen.

The appropriation of large sums to prepare a topographic map of Maryland affords a reason for stating the objects of such a map, and such a statement might suffice simply as an explanation. But to meet the educational purpose of the Maryland Survey more is required, and this something more is supplied by Mr. Gannett's article on the aims and methods of cartography with especial reference to topographic maps. The methods now in use in extensive surveys were developed by Mr. Gannett and his assistants and are characteristically original. 
In their present development they constitute the most practical methods known, because they are the most economic while they are also adequately accurate.

The succeeding article by Dr. Mathews on 'Maps and Map Makers of Maryland' is of much historic interest. Dr. Mathews has ably assisted Professor Clark in his effort to make the Survey of Maryland a success, and to them both, as well as to the Geological Commission, belongs the credit of raising the standard of economic surveys to a grade that few can reach and none have surpassed.

\section{BAILEY WILlis.}

La vie sur les hauts plateaux. Par le Professor A. L. Herrera et le Dr. D. Vergara Lope. Published by A. L. Herrera, Museo Nacional, Mexico. 1899. 4to. Pp. 786. Price, \$6. This remarkable work won the Hodgkins prize of the Smithsonian Institution, and now, translated from Spanish into French, is published in beautiful form through the munificence of President Diaz, of Mexico, to whom it is appropriately dedicated.

Professor Herrera, as the best type of a man of science, is an honor to our sister republic. His epoch-making ideas on the subject of museums have been very influential in France.

The present important volume is on matters for whose investigation the authors are most advantageously situated, having lived that life on the high plateaux of which they so ably treat.

The book opens with a chapter on the relief of both continents; the distribution of the great plateaux; their relations, ethnographic and hygienic. Chapter II. is on the vertical distribution of vegetable life and the phenomena of adaptation in the species of high altitudes. This is particularly rich in regard to the flora of Mexico and especially the Valley of Mexico. The action of the increased intensity of the sunlight is exhaustively studied.

Chapter III. devotes two hundred pages to the vertical distribution of animals, with the phenomena of adaptation, and in particular the influence of rarefied air. A study is made of mountain sickness as exhibited by animals.

Chapter IV. passes to the vertical distribu- tion of mankind. Chapter V. is devoted to anthropometry and physiology of man at high altitudes. Worthy of note is the part on digestion, illustrated by considerations on the food supply of the City of Mexico. Chapter VI. is very short, treating of atmospheric pressure in geologic epochs and its supposed influence on organic evolution. Chapter VII. is largely taken up with experiments on the action of rarefied air. Chapter VIII. is on combustion and fermentation at high altitudes. Book II., applications, begins with Chapter IX., on typhus and scrofula at high altitudes. But of intense interest, of universal importance, is the matter of Chapter X., on the treatment of tuberculosis by altitude.

Statistics prove that the maximum of mortality from this dread destroyer pertains to low regions, the minimum to high. In more than 60 cases the curve of mortality rises as that of altitude descends.

In Mexico, even among the poor and the soldiers, there are less deaths from tuberculosis than in the low regions of Europe. For a thousand victims in regions below 500 meters there are only 255 in regions above 500 . In Mexico out of 100 persons the parents of 3 will have died of tuberculosis; in Lima the parents of 18 .

A residence at high altitudes is indicated for persons with hereditary or any other predisposition toward tuberculosis; for persons with defective chest-conformation or respiratory capacity, or in whom inflammatory affections have been incompletely cured. Even for animals the data show at high altitudes a certain immunity against tuberculosis.

In 1885 of 73,000 cattle killed at the general abattoir of the City of Mexico only 45 were tuberculous, while in England the proportion rises as high as 20 in 100

It is known, say our authors, that in tuberculosis the climate of high altitudes, even for those far advanced, prolongs life. What is it, then, that can diminish the number of cases or help those already attacked? Our authors attack this momentous question in the true spirit of experimental science. The illumination by the solar rays attains its maximum at high altitudes, and experiment proves that light 